\title{
A Brief Analysis of How Metaphor Awareness Benefits College English Vocabulary Teaching \\ Ke Gao
}

\author{
School of Foreign Studies Xi'an University 710065
}

Keywords: Cognitive linguistics, Metaphor, conceptual metaphor, Metaphor awareness, Image schema

\begin{abstract}
This essay aims to explore how metaphor awareness in discipline of cognitive linguistics will benefit vocabulary teaching and learning in College English Class. The notion 'metaphor awareness' mentioned here is mainly for teachers in their teaching, which implies recommendations such as teacher training, more teaching materials supplied, an interactive platform such as forums, web-zone, twitter, for sharing teaching ideas and experiences to better English teaching in class, and help students with their English vocabulary learning.
\end{abstract}

\section{Introduction}

English, as a foreign language in China, plays a rather interesting role, as it is believed that 'English is more than a communication tool, but one of the defining measures of life's potential' (Tsui $\&$ Tollefson, 2007: 22). Therefore, English teaching and learning boomed even it is of little current use for most Chinese people.

As is seen that there are many studies show that English teaching can benefit from cognitive linguistics teaching in some sense, and in addition, language is from life and for life, it will be more comprehensible if language is taught from a cognitive view with more comprehensible input.

\section{Theoretical Base}

\section{What is Metaphor}

The word 'metaphor' comes from the Greek word 'metapherein', which means 'to carry over' (Lang, P.: 1994:8 ). To be more specific, it is the transfer from one domain of experience to another domain of experience. For the essence of metaphors, Aristotle once claimed that metaphors should be regarded as a kind of decoration or ornament (Aristotle 1909:63). While Richards (1956) points out the function of metaphors is that metaphors convey meaning.

\section{What is Cognitive Linguistics View}

Cognitive linguistics starts to 'discover the subtle workings of language' (Tendahl, 2009: 112) and suggest that acquiring linguistic knowledge is essentially the same with learning other kinds of knowledge in mental process. As Croft and Cruse (2004: 2) claim that, the cognitive ability in understanding language is quite similar with other cognitive tasks such as visual perception and motor activity. Different from general linguistics, which announces language is located in the language faculty with its own rules and is isolated from other mental modules such as memory and emotion, cognitive linguistics views 'language as an important instantiation of human's general cognitive abilities that are not isolated' (Tendahl, 2009:113)

\section{The Essence of Metaphors from Cognitive Linguistics: Image Schema.}

Tendahl (2009: 122) comments, in cognitive linguistics, the key words for the grounding of metaphor are experience and embodiment, in which' experience' is symbolised by 'image schemas'. As Holme (2004: 23) defines, 'Image schemas are conceptual resources provided by some of our earliest perceptions of ourselves as embodied creatures that are subject to physical experience.' To be more specific, image schemas are the mental images which are based on concrete interactions with the physics of the world. From lakoff (1987: 272-276), there are basically eight schema images of which the 'container schema', the 'part- whole schema', the 'link schema', the 'source-path-goal schema' and the 'centre- periphery schema' are more frequent in metaphors. 


\section{How Metaphor Awareness Benefit Vocabulary Teaching}

Sokmen (1997) once highlights some key principles in teaching vocabulary: 'Build a large sight of vocabulary; Integrated new words with old ones; and Provide a number of encounters with a word.'From those suggestions, it is obvious that it is very encouraged to teach word by connecting it with other things. And this is just the basic concept of cognitive linguistic perspective in vocabulary teaching. Lakoff and Johnson (1980:3) observe that metaphor is pervasive not only in language, but also in thought and action, metaphor awareness will not simply exist in how language utterances are formed and used, but also in how language can be understood, explored and taught. Below are how metaphor awareness benefits vocabulary teaching

With Metaphor Awareness, Word Collocations and Combinations will become More Comprehensible for Chinese Learners.

As metaphors can relate abstract concepts to concrete things, and most words have their own meaning as well as functions, with metaphor awareness, word collocations and combinations will be more sensible. Back at the conceptual level, it is not difficult for Chinese students to understand 'time' as a concept from a comparison given by Alverson (1994:67-76), but the collocations and word combinations are difficult to distinguish and remember. From Alverson's research, it shows that both in English and Chinese, time can be seen as the following five concepts:

'a partible entity' (save time, waste time, etc.); 'an effect' (time passes, time heals, etc.);

'a medium in motion' (flow of time, time waits for no one), 'time is a course' (a lone time, time and time again, etc.); 'a measurement' (set the clock ahead, the sand of time, etc.)

From the vocabulary lists of that series of student course books, it demonstrates that phrases like 'spend time', 'save time' do not always appear in the same reading passage. That is to say, how 'time', as an English word being used, is taught separately, which makes it less connected for students to remember and use. However, with metaphorical competence in cognitive linguistic view, time shares some common features with money, such as limit, valuable, important, precious, etc., so many verbs used for 'money' can also be used to describe time. In addition, time shares some points with space, which can be concreted to a walking way like a 'path'. In this sense, we get time as a meaning of spots, or points for doing something. It is obvious that to by metaphors, the concepts transferred are not isolated as individual concepts, but a structure. Hence, with metaphor awareness, it is not individual words that are taught, but a series of related lexical items. And this conceptualised structure being built with linguistic lexical items in the surface, it will be more comprehensible.

With Metaphor Awareness, Complex Meaning can also be Presented with Simpler Words.

Metaphor, which is often perceived as an essentially literary device, is revealed by more and more modern philosophical and linguistic research that far from being restricted to literacy language, it is part of cognition. Words, as the most basic language competence, convey meaning, show human thoughts, feelings, etc. As Punter (2007:13) suggests, since metaphors would offer perceived resemblances where a concept, an idea or an emotion might be difficult to grasp in language; on the other side, that is to say, words that represent abstract concepts through metaphors would be easier. This would be a bidirectional function of metaphorical meaning, which are 'comprehensible input' and 'comprehensible output'. Therefore, raising metaphor awareness in vocabulary teaching will help students to explore deeper meaning and usages of more basic words, which will be a great relief for learners to express themselves. There are also many metaphorical competences embodied in language with 'heart', 'neck', 'mouth', etc. Such as 'warmhearted', 'the mouth of the river', 'bottleneck', 'neck and neck', 'the nose of a plane', 'the foot of the mountain', 'the back / leg of the chair'. Apart from examples above, there are also metaphors embodied in idioms. For instance, 'Out of sight, out of mind.' 'Two heads are better than one.' 'An eye for an eye, a tooth for a tooth.' etc. According to the studies by Ciesicka (2006, 2008), language learners often interpret idioms via a literal reading of the expressions. If teachers can explore a little deeper of those basic words and briefly introducing those to students, it will be a great help to evoke students' potential to make full use of the language resources they have, however limited. 


\section{With Metaphor Awareness in English Class, Vocabulary Teaching will be more Interesting and Motivating.}

Motivation is an efficient element to promote self-regulated learning (Billing, 2007:27). Billing (2007:18) continues, 'motivation and need to achieve are important in problem-solving, and are both based on goal orientation and self-concepts derived from the perceived reason for prior success or failure.' There are two factors mentioned here, one is the purpose and the other is passion from deep inside. For those senior high school students in China, English is far away from real communicative use, but an exam tool. In this case, there seems to be one factor exists, but for adolescent students, it is the latter one that may make a bigger contribution. Then how to form a more enjoyable journey to learn English will help.

From Ellis's (1995b:14) view, it is necessary for vocabulary teaching to arrange some metacognitive strategies, since the greater the depth of processing involved in the learning, the more secure and long term the learning is likely to be. Billing (2007:29) also suggests that teaching should better use multiple examples. And Cox(1997) emphases that, 'teachers should focus on the transfer of meta- cognitive skills, and encouraging active learners'. As 'our word knowledge is organised by mental lexicon' ( raised by Thornbury, 2005:16), raising metaphor awareness in vocabulary teaching is a wise choice to explore deeper cognition in words, and even more than that, such as culture, tradition, history, religions, which are fruitful knowledge behind language that helps form the mental lexicon. With these awareness, language teaching, especially vocabulary teaching will be much more like stories with a variety of plots.

\section{Conclusion}

Words are like seashells : they have their voices, and are full of old echoes, and if we take up these terms, and examine them, and sort them according to their ages and various sources, we find that they have much to tell us of the history of English seamanship.'(Smith, 1933:2)

Words convey most meaning of languages, and vocabulary learning plays a rather significant role in language teaching. Since 'A second language learner is different from a child acquiring a first language, in terms of both the learners' characteristics and the environments in which L1 and L2 acquisition typically occur' (Spada, 2006:29). More specifically, the learning of vocabulary is primarily by incidental means, such as unconscious exposure to and experience of using words, and then by approaches such as Lexical approach, which stresses the importance of learning 'lexical chunks' ( Whole, communicatively significant phrases ), etc. Language teaching is always on the way of developing.

\section{References}

[1] Adamson, B. (2002) Barbarian as a foreign language: English in China's schools. World Englishes 21 (2), 181-199.

[2] Aristotle, (1909) The Basic Works of Aristotle, in Richard McKeon New York: Rndom House, 1941, 1457b . 6-7.

[3] Cook, V. (1999) ' Going beyond the native speaker in language teaching '.TESOL Quarterly 33(2) :185-209.

[4] Ellis,N\&D, Laesen- Freeman. 2006. ' Language Emergence : Implications for applied linguistics '. Applied Linguistics 27, 4 :558-589.

[5] Krashen,S.D.\& Terrel,T.D. (1983) The Natural Approach : language acquisition in the classroom . Oxford : Pergamon.

[6] Lakoff, G. \& Johnson, M. (1980) Metaphors We Live By. Chicago ; London : University of Chicago Press

[7] Lewis,M. (1993) The Lexical Approach. Printed in England by Commercial Colour Press, London E7.

[8] Lakoff, G. \& Johnson, M. (1980) Metaphors We Live By. Chicago ; London : University of Chicago Press 
[9] Lewis,M. (1993) The Lexical Approach. Printed in England by Commercial Colour Press, London E7.

[10] Littlemore, J.\& Low, G. 2006. Metaphorical competence, second language teaching and communicative language ability. Applied Linguistics 27 (2) :268-294.

[11] Punter,D. 2007. Metaphor. New York : Routledge. Richards, I. A. The Philosophy of Rhetoric [M]. Oxford University Press. 1936.

[12] Routledge and Kegan Paul, 1979. See I. Scheffler, Beyond the Letter (Routledge and Kegan Paul, 1979), p. 83, discussin the intuitionistic approach to metaphor. 